|| Print ISSN: 2589-7837 || Online ISSN: 2581-3935 || International Journal of Medical Science and Diagnosis Research (IJMSDR)

Available Online at www.ijmsdr.com

NLM (National Library of Medicine ID: 101738824)

Original Research Article

Volume 4, Issue 11; November: 2020; Page No. 24-27

\title{
ENDODONTIC CONSIDERATION IN HAEMOPHILLIAC PATIENTS: A REVIEW
}

Naveen K Kumar ${ }^{1}$, Prasada L Krishna ${ }^{2}$, Safeer Mohammed ${ }^{3}$, Thameem Aysha ${ }^{4}$

${ }^{1}$ Reader, Dept of Conservative Dentistry and Endodontics, KVGDC, Sullia.

${ }^{2} \mathrm{HOD}$, Dept of Conservative Dentistry and Endodontics, KVGDC, Sullia.

${ }^{3}$ Post Graduate Student, Dept of Conservative Dentistry and Endodontics, KVGDC, Sullia.

${ }^{4}$ Bachelor of Dental Surgery, KVGDC, Sullia.

Conflicts of Interest: Nil

Corresponding author: Naveen K Kumar

DOI: https://doi.org/10.32553/ijmsdr.v4i11.703

\section{Abstract:}

One who manage dental patient who has a bleeding disorder should have knowledge about the coagulation system and the patient's specific coagulation defect. Such patient can receive quality comprehensive dental care, provided appropriate preoperative planning and evaluation with the patient's physician or hematologist is accomplished. Patient should be provided appropriate replacement therapy before the dental procedure, selection of conservative treatment approaches, and use of local hemostatic measures to facilitate hemostasis.

\section{Introduction:}

A deficiency of either clotting factor VIII (haemophilia A) or IX (haemophilia B) leads to the disorder called haemophilia which is a hereditary $X$-linked recessive disorder. ${ }^{1,2}$ The prevalence of haemophilia A (classic haemophilia) is estimated at 1 in 6000 men while that of haemophilia B (or Christmas disease) has a prevalence of 1 in 30000 men. $^{7}$ Heamophillia normal ranges from 50-100 $\mathrm{lU} / \mathrm{dL}$, and it is considered mild if it ranges between 6 and $40 \mathrm{lU} / \mathrm{dL}$, moderate if it ranges between 2 and $5 \mathrm{IU} / \mathrm{dl}$ and severe if plasma activity is less than $1 \mathrm{IU} / \mathrm{dl}^{3}$

The clinical features of both types of haemophilia are same: spontaneous or traumatic haemorrhages; muscle haematomas; haemophilic arthropathy caused by recurrent bleeding into target joints; and bleeding into the CNS. Without suitable exogenous clotting factor replacement therapy these manifestations of the disease could result in deadly sequelae, which negatively impact patient's quality of life and decreases their life expectancy. ${ }^{4}$

Excessive and unexplained bleeding have been reported since ancient times. ${ }^{5}$ The spread of haemophilia from mothers to sons was first described in the early 19th century. In 1803, the Philadelphia physician Dr. John Conrad Otto documented that a bleeding condition was hereditary and mainly affected males. He drew the disease back through three generations to a woman who had settled near Plymouth, New Hampshire in 1720. The word "haemophilia" first appeared in a description of a bleeding disorder condition at the University of Zurich in $1828 .{ }^{6}$ It is called the "Royal Disease." Queen Victoria of England was a carrier of the hemophilia gene and then passed the disease on to several royal families. ${ }^{7}$
Bleeding is sometimes the first or only sign of a mild haemophillia after dental extractions. ${ }^{8}$

A Factor VIII level above $25 \%$ causes very mild disease; the patient can generally lead a relatively normal life and may remain undiagnosed, but there can be prolonged bleeding following trauma or surgery. Absence of bleeding from socket cannot always rule out hemophilia. ${ }^{9}$ An interesting fact is the clotting time is within normal limits even at $1-2 \%$ of Factor VIII. ${ }^{10}$

Fear of bleeding during dental procedures has been an enigma to both dentist as well as patient. Hemophilia patients are categorised as special patients from a dental point of view, as the highly vascular oral cavity is definitely a hotspot for hemorrhage in this group of patients. It is not infrequent that a dentist diagnoses a bleeding disorder at first on performing routine dental treatments. A very good knowledge of methodical approach is necessary for any dental professional inorder to handle hemophiliacs the absence of which can lead to terrible consequences. ${ }^{4}$ The purpose of this review article was to consider endodontic management of patients suffering from haemophilia.

\section{CLINICAL LABORATORY TESTS}

If a patient is suspected to have haemophilia, the next step is blood investigations. The tests done to evaluate the status of primary haemostasis include:

1. Complete blood count/ platelet count

2. Bleeding Time

These tests evaluate the platelet count and morphology, and function and health of the capillaries. The tests done to evaluate the status of secondary haemostasis are [Table: $1]^{11,12}$ 
Table 1: Tests done to assess $2^{0}$ haemostasis in haemophilia

\begin{tabular}{lll}
\hline $\begin{array}{l}\text { S } \\
\text { No. }\end{array}$ & TEST & $\begin{array}{l}\text { Status } \\
\text { Haemophillia A }\end{array}$ \\
\hline 1. & Prothrombin time (PT) & Not Affected \\
\hline 2. & $\begin{array}{l}\text { Activated } \\
\text { Thromboplastin Time (APTT) }\end{array}$ & Partial \\
\hline 3. & $\begin{array}{l}\text { Thromboplastin Generation Test } \\
\text { (TGT) }\end{array}$ & Increases \\
\hline
\end{tabular}

Next step in the diagnosis is Factor VIII assay. This is done to identify whether Factor VIII or Factor IX is deficient. It is of two types:

QUAITATIVE: This assay tells us which factor (VIII or IX) is deficient.

QUANTITATIVE: This analysis tells the exact percentage of deficient factor.

\section{DIAGNOSIS}

Although the disease is congenital it may or may not manifest clinically for several years. ${ }^{11}$. Initially it is musty to take proper medical and dental history of the patient.

Health questioning should cover:

(a) History of bleeding after post surgery,

(b) Past and present drug history ${ }^{13}$,

(c) History of bleeding problems among relatives ${ }^{14}$ and

(d) Illness associated with potential bleeding problems ${ }^{15}$.

The diagnostic laboratory findings in hemophilia can be summarized as follows below: Activated Partial Thromboplastin Time (APTT): Prolonged, Prothrombin time (PT) : normal, Bleeding Time (BT) : normal and low Factor VIIIC. Factor VIII assay is generally required because even the APTT may be normal in mild cases.

\section{GENERAL MANAGEMENT}

Factor VIII must be substituted to a level adequate to safeguard hemostasis if bleeding starts or is expected. Procaine Factor VIII or recombinant Factor VIII can be used as a replacement missing factor. ${ }^{16}$ One unit of Factor VIII concentrate per $\mathrm{kg}$ of body weight raises the Factor VIII level by $2 \%$ and hence an average $70 \mathrm{~kg}$ individual would require infusion of 3500 units to raise the factor level from less than $1 \%$ to $100 \%$. Thus a simple formula can be used as:

Dose to be infused (Units) $=$ \{Weight $(\mathrm{Kg}) \times$ Increment needed $(\mathrm{U} / \mathrm{dl})\} / 2$

In mild haemophilia patients, antifibrinolytics and desmopressin such as tranexamic acid may be pleasing. ${ }^{17}$ Desmopressin, a synthetic analogue of vasopressin is available in the market for intranasal spray and intravenous infusions. It gives adequate transient raise in coagulation factors in some patients with mild to moderate haemophilia which helps in arrest bleeding. Tranexamic acid is a synthetic derivative of amino acid lysine. It is available for topical application and systemic treatment. The anti-fibrinolytic agent Epsilon amino caproic acid (EACA) which can be given orally or intravenously is a potent inhibitor of initial clot dissolution. Postsurgical use of EACA has been shown to decrease the quantity of factor required to control bleeding when used in conjunction with pre-surgical concentrate infusion sufficient to raise the plasma Factor VIII and IX levels to $50 \%$. A $50 \mathrm{mg} / \mathrm{kg}$ body weight EACA is given as a regime orally as a $25 \%$ oral rinse every six hours for seven to ten days appears adequate as an adjunct. Still tranexamic acid is 10 times more potent compared to EACA.

There are no basic differences in the oral health problems of the hemophiliac and those of the average individual; however, optimal dental health is more of a necessity for the hemophiliac since the problems posed by dental surgery. Therefore, it is reasonable to expect that today's dental practitioners should provide the care so desperately needed by such patients. ${ }^{18}$

Many of the defects in the coagulation process lead a hazard to surgery and to local anesthetic injections but in general teeth eruption and exfoliation occurs without problems as such. Close coordination is necessary between the dentist and the physician to plan safe and comprehensive dental care. Educating parents and preventive dentistry should be initiated as early as possible. Local anesthetic injections can be followed by persistent bleeding for days or weeks; the hemorrhage cannot be controlled by mere pressure and may be life threatening.

Difficulties in the management of a hemophiliac dental patient include the following:

1. Dental neglect necessitating frequent extractions

2. Trauma and surgery

3. Factor VIII inhibitors (recombinant F VIla is an alternative solution). ${ }^{19}$

Tendency for bleeding can be aggravated by NSAIDs. Alternatives are acetaminophen, codeine and Cox-2 inhibitors. Local anesthetic regional blocks or lingual infiltrations are contraindicated in the absence of Factor VIII replacement because of the risk of hemorrhage hazarding the airway and can be life threatening. ${ }^{20}$

Even submucosal infiltrations have caused hematoma formation. If Factor VIII replacement therapy has been given, regional LA can be admimistered provided the Factor VIII level is maintained above $30 \%$. Prior to 
mandibular block injection, prophylactic factor replacement has to be done. Webster reported $80 \%$ chance of hematoma formation for hemophiliacs not treated with prophylactic factor replacement. Infiltrations, intraligamentary, intraosseous or intrapulpal injections are more safer. ${ }^{21}$

\section{ENDODONTICS}

In haemophiliac patients, root canal treatment is preferred instead of extraction wherever possible due to chances of uncontrolled bleeding. Extravasation of blood in the oropharyngeal area or in the pterygoid plexus can be life threatening. So, Inferior alveolar nerve block and lingual infiltration are usually contraindicated unless the factor levels are above $30 \%$ by replacement therapy. Acetaminophen and narcotics are preferably used for postoperative pain while aspirin or any other NSAIDS warrants haematological consultation because of their effect on platelet aggregation. ${ }^{22}$

Rubber dam isolation is must inorder to prevent laceration of soft tissue by rotary instruments where notches should be placed on both buccal and lingual surfaces with a bur to ensure proper placement of clamp without hurting the gingiva. ${ }^{23}$

In severe hemophiliacs endodontic treatment can be usually carried out under anti fibrinolytic cover. ${ }^{5}$ During irrigation, sodium hypochlorite should be used in all cases followed by use of calcium hydroxide paste to control bleeding. ${ }^{24}$ Apex locators should be preferably used for measuring working length of the canal to minimise the need for intra oral periapical (IOPA) radiographs as repeated placement of film can lead to injury and bleeding in the mucosa. Instrumentation and filling should not be done beyond the apical region of a vital tooth. Inorder to prevent over instrumentation, non-vital teeth should be treated at least 2 to $3 \mathrm{~mm}$ short of the radiographic apex. Cotton rolls may also cause bleeding from oral mucosa in dry state and should be wetted before removal to avoid injuring it. High speed vacuum evacuators and saliva ejectors may also leads to trauma on the floor of mouth and thus lead to haematoma formation. They should be placed by resting them on a gauze swab in the floor of the mouth, thus avoid injury. ${ }^{25,26,27}$ Intracanal injection of local anaesthetic solution containing adrenaline or topical application (paper points) of adrenaline (1:1,000 ratio) can be used to reduce bleeding.

\section{SURGICAL ENDODONTICS}

Endodontic surgeries should be performed in a single appointment. A Factor VIII level of 50 to $75 \%$ is required. The importance of local aids to prevent postoperative bleeding cannot be overemphasized. Only mild hemophiliacs requiring such surgeries can be managed usually without factor replacements.

Desmopressin and tranexamic acid are primary alternatives. Desmopressin can be given as a intravenous infusion over $20 \mathrm{~min}$ of $0.3-0.5 \mu \mathrm{g} / \mathrm{kg}, 30$ to $60 \mathrm{~min}$ prior to the surgical procedure. This results in a thrice fold rise in Factor VIII activity with a mean half-life of 9.4h. Intranasal spray of $1.5 \mathrm{mg}$ per $\mathrm{ml}$ with each $0.1 \mathrm{ml}$ pump spray is an alternative, but it requires a tenfold higher dose of desmopressin to get a maximal two fold increase in Factor VIII activity after $90 \mathrm{~min}$, limiting treatment to those haemophiliac patients whose basal factor levels are sufficiently high. Tranexamic acid literally decreases blood loss. ${ }^{28}$ Systemically, it is given in a dose of $1 \mathrm{~g}(30 \mathrm{mg} / \mathrm{kg})$ orally, four times a day starting at least $1 \mathrm{~h}$ preoperatively for surgical procedures. Tranexamic acid infusions can be given as $10 \mathrm{mg} / \mathrm{kg}$ in $20 \mathrm{ml}$ normal saline over $20 \mathrm{~min}$, then $1 \mathrm{~g}$ tds orally for five days (child dose is $20 \mathrm{mg} / \mathrm{kg}$ ). ${ }^{16}$

Trauma during surgery should be as minimal as possible and suturing is done to immobilize gum flaps to fasten healing. Vicryl sutures are best preferred whereas catgut is best avoided. Non-resorbable sutures such as black silk should be removed at five to seven days. Reflecting lingual tissues are best avoided. Acrylic protective splints can be more trouble than helpful by containing debris and promoting sepsis. Packing of surgical site is usually unnecessary if replacements have been sufficient. If required, a little oxidized cellulose (surgicel ${ }^{\circledR}$ ) soaked in tranexamic acid may be placed. Collagen or cyanoacrylate or fibrin glues can also be used. Use of fibrin glue and swish and swallow rinses of tranexamic acid before and after the procedure is a cost-effective solution. A diet of cold liquid or semisolid food should be taken for six to ten days postoperatively. Care should be taken to watch for hematoma formation manifesting as dysphagia, swelling or hoarseness. ${ }^{29}$ Infection induces fibrinolysis and so antimicrobials such as amoxicillin $500 \mathrm{mg}$ four times daily should be given post treatment for a full course of seven days to reduce the chances of secondary haemorrhage. ${ }^{29,30}$

\section{CONCLUSION}

With sufficient precautions and proper protocol, root canal treatment can be performed without major risks in haemophilic patients. Early dental care is necessary in such patients to avoid invasive procedures at a future date. So patient education regarding oral hygiene is of prime importance. A thorough understanding of the problems especially haemophilia helps to do a systematic evaluation and anticipate potential dangers rather than being caught unawares with inadequate and desperate local hemostatic measures. 


\section{REFERENCES}

1. Liras A, Segovia C, Gabán AS. Advanced therapies for the treatment of hemophilia: future perspectives. Orphanet J Rare Dis 2012;7:97.

2. Berntorp E, Shapiro AD. Modern haemophilia care. Lancet 2012;379:1447-56. Price M. Case Closed: Famous Royals Suffered From Hemophilia. Science now. 2009 Oct;8.

3. Atara RR, Shenoi PR, Mute WR, Makade CS, Mahajan AK. Endodontic management of patient with hemophilia. International Journal of Prosthodontics \& Restorative Dentistry. 2013 Jul 1;3(3):101.

4. Kumar JN, Kumar RA, Varadarajan R, Sharma N. Specialty dentistry for the hemophiliac: Is there a protocol in place?. Indian Journal of Dental Research. 2007 Apr 1;18(2):48.

5. Aronova-Tiuntseva $Y$, Herreid CF. Hemophilia:"The royal disease". National Center for Case Study Teaching in Science Case Study Collection. http://sciencecases. lib. buffalo. edu/cs/files/hemo. pdf. Accessed. 2005 Apr;18.

6. Santagostino E, Fasulo MR. Hemophilia A and hemophilia B: different types of diseases?. InSeminars in thrombosis and hemostasis 2013 Oct (Vol. 39, No. 07, pp. 697-701). Thieme Medical Publishers.

7. Hoffbrand VA, Catovsky D, Edward GD, Tuddenham. Post graduate haematology, 5th ed. Blackwell Publishing: London; 2005.

8. Greenberg $M$, Glick $M$. Burket's Oral Medicine diagnosis and treatment, 10th ed. JB Lippincott Company: Philadelphia; 2002

9. Rajendran R, Sivapathasundaram B, editors. Shafer's textbook of oral pathology. Elsevier: New Delhi; 2006.

10. Rajendran R, Sivapathasundaram B, editors. Shafer's textbook of oral pathology. Elsevier: New Delhi; 2006.

11. Chaudhuri SK. Concise Medical Physiology. 5th ed. New Central Book Agency (P) Ltd.; 2004.

12. Meechan JG, Greenwood M. General medicine and surgery for dental practitioners. Part

13. haematology and patients with bleeding problems. $\mathrm{Br}$ Dent J. 2003; 195(6): 305-10.

14. Lockhart PB, Gibson J, Pond SH, Leitch J. Dental management considerations for the patient with an acquired coagulopathy. Part 1: Coagulopathies from systemic disease. Br Dent J. 2003; 195(8): 439-45.

15. Gupta A, Epstein JB, Cabay RJ. Bleeding disorders of importance in dental care and related patient management. JCDA. 2007; 73(1): 77-83.
16. Scully C, Watt-Smith $P$, Dios RD, Giangrande PL. Complications in HIV-infected and non-HIV infected haemophiliacs and other patients after oral surgery. Int J Oral Maxillofac Surg 2002;31:634-40.

17. Powell D, Bartle J. The hemophiliac: Prevention is the key. Dent Hyg Chic 1974;48:214-9.

18. Snyder DT, Penner JA. Preventive and restorative dental care for the hemophiliac. J Mich State Dent Assoc 1970;52:6-8.

19. Edwards $\mathrm{CR}$, Bouchier IA, Haslett C. Davidson's Principles and practice of medicine, 17th ed. Churchill Livingston: Edinburgh; 1995.

20. Lucas ON. The use of hypnosis in hemophilia dental care. Ann NY Acad Sci1975;240:263-6.

21. Bjorndal AM. Endodontic treatment of an upper first molar in a hemophiliac. Oral Surg Oral Med Oral Path 1961;14:472-3.

22. Evans BE. The role of the dentist in the comprehensive management of haemophilia.

23. Southeast Asian J Trop Med Public Health. 1979; 10: 285-94.

24. Evans BE. Consideration in the dental treatment of the haemophiliac patient. J Dent Guid Counc Handicap. 1976; 15: 3-7.

25. Guidelines for Dental Treatment of Patients with Inherited Bleeding Disorders. Dental Committee, World Federation of Haemophilia.

26. Evans BE. Consideration in the dental treatment of the haemophiliac patient. J Dent Guid Counc Handicap. 1976; 15: 3-7

27. Evans BE, Aledort LM. Haemophilia and dental treatment. J Am Dent Assoc. 1978; 96: 827-34.

28. Guidelines for Dental Treatment of Patients with Inherited Bleeding Disorders. Dental Committee, World Federation of Haemophilia.

29. Borea G, Montebugnoli L, Capuzzi P, Magelli C. Tranexamic acid as a mouthwash in anticoagulanttreated patients undergoing oral surgery. An alternative method todiscontinuing anticoagulant therapy. Oral Surg Oral Med Oral Pathol 1993;75:2931

30. Wein FS. Endodontic therapy. 5th ed. Mosby: Missouri; 1996.

31. Richter S, Stratigos GT. Management of a hemophiliac with a dental abcess and subsequent root canal therapy and apicoectomy. N Y State Dent J 1973;39: 11-4. 